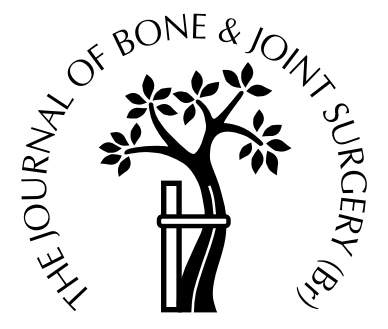

\title{
Hip surveillance in children with cerebral palsy
}

\author{
IMPACT ON THE SURGICAL MANAGEMENT OF SPASTIC HIP \\ DISEASE
}

\author{
F. Dobson, R. N. Boyd, J. Parrott, G. R. Nattrass, H. K. Graham \\ From the Royal Children's Hospital, Melbourne, Australia
}

$\mathbf{W}$ Te studied prospectively the impact of a hip surveillance clinic on the management of spastic hip disease in children with cerebral palsy in a tertiary referral centre. Using a combination of primary clinical and secondary radiological screening we were able to detect spastic hip disease at an early stage in most children and to offer early surgical intervention. The principal effect on surgical practice was that more preventive surgery was carried out at a younger age and at more appropriate stage of the disease. The need for reconstructive surgery has decreased and that for salvage surgery has been eliminated. Displacement of the hip in children with cerebral palsy meets specific criteria for a screening programme. We recommend that hip surveillance should become part of the routine management of children with cerebral palsy. The hips should be examined radiologically at 18 months of age in all children with bilateral cerebral palsy and at six- to 12-monthly intervals thereafter. A co-ordinated approach by orthopaedic surgeons and physiotherapists may be the key to successful implementation of this screening programme.

J Bone Joint Surg [Br] 2002;84-B:720-6.

Received 1 May 2001, Accepted after revision 30 October 2001

Displacement of the hip and equinus are the two most common deformities in children with cerebral palsy. ${ }^{1}$ The incidence of hip displacement in cerebral palsy is related to the severity of involvement, varying from $1 \%$ in children with spastic hemiplegia, up to $75 \%$ in those with spastic quadriplegia. ${ }^{2,3}$ The natural history of spastic hip disease is

F. Dobson, BAppSc (PT), PGDip HlthRes, Research Physiotherapist R. N. Boyd, MSc PT PGDip Biomech, Senior Research Physiotherapist J. Parrott, BAppSc (PT), Research Physiotherapist

G. R. Nattrass, MD, FRCS C, FRACS, Consultant Orthopaedic Surgeon H. K. Graham, MD, FRCS Ed, FRACS, Professor

Orthopaedic Department and Hugh Williamson Gait Laboratory, Royal Children's Hospital, Flemington Road, Parkville 3052, Victoria, Australia.

Correspondence should be sent to Professor H. K. Graham.

(C)2002 British Editorial Society of Bone and Joint Surgery 0301-620X/02/512398\$2.00 progressive lateral displacement of the hip secondary to spasticity and muscle imbalance in the major muscle groups around the hip. Displacement may progress to severe subluxation, secondary acetabular dysplasia, deformity of the femoral head, dislocation and painful degenerative arthritis. ${ }^{4,5}$ The long-term effects of dislocation of the hip can be disastrous for individual patients leading to pain and loss of the ability to sit comfortably in up to $50 \%$ of cases. ${ }^{6}$ Other problems include difficulty with perineal care and personal hygiene, pelvic obliquity and scoliosis, poor sitting balance and loss of the ability to stand and walk. ${ }^{5,7-10}$

The aim of the management in children with spastic hip displacement is to maintain flexible, well-located and painless hips with a symmetrical range of movement. The key to achieving this goal is early identification and intervention. $^{2,4,11}$ Stability of the hip and acetabular development are more certain if the femoral head is well located in the acetabulum before the age of five years. ${ }^{12-14}$ It is therefore important to refer children whose hips are at risk, for orthopaedic management in time to prevent progressive displacement and to centralise the femoral head well before that age. ${ }^{15}$ Unfortunately, displacement of the hip is silent in the initial stages and difficult to detect by physical examination alone. Early detection requires a combination of regular clinical examination of the range of abduction of the hip, and regular radiographs of the hips. ${ }^{2,4,11}$ Delayed detection often restricts surgical options. The missed opportunity for simple preventive surgery may result in the need for more complex reconstructive or salvage surgery with associated increased morbidity, mortality and complications. ${ }^{2,4,16-23}$

Surgical indications are usually based on the degree of displacement of the femoral head and acetabular dysplasia. The migration percentage as described by Reimers ${ }^{24}$ and the acetabular index described by Hilgenreiner ${ }^{25}$ are the conventional measurements of displacement of the hip and acetabular dysplasia in young children with cerebral palsy. ${ }^{1}$ Reimers $^{24}$ found that among normal children, the 90th centile for migration percentage at four years was $10 \%$ with spontaneous migration of less than $1 \%$ per year. Systematic screening is required to identify all children who are at risk of spastic displacement of the hip but there are no currently agreed guidelines. ${ }^{9,11,24}$ In large metropolitan centres, there 
are considerable numbers of children who require regular monitoring and many are lost to follow-up. In our centre, there were large numbers of older children with advanced spastic hip disease causing severe symptoms whom we were unable to manage satisfactorily by reconstructive and salvage surgery. Complication rates were high and many children had persistent hip displacement, pain and fixed deformity.

In August 1997, we established a hip surveillance clinic (HSC) for children with cerebral palsy in parallel with the existing surgical clinics for such children. The primary aim of this new clinic was to provide a comprehensive system for the early detection and management of spastic hip displacement and to educate parents, carers and referring agencies. The secondary aim was to monitor the outcome of all aspects of the service, including detection and intervention rates and the outcome of conservative and operative intervention. We have prospectively studied the impact of this clinic on the management and outcome of spastic hip disease during the first three years since its inception. Based on the analysis of our preliminary results, we have made recommendations for hip surveillance in children with cerebral palsy.

\section{Patients and Methods}

The clinic is based in a tertiary referral centre and is coordinated by two research physiotherapists with specialist training in the management of hips in children with cerebral palsy including radiological measurement and standardised clinical examination. It runs alongside the weekly orthopaedic clinic for children with cerebral palsy, which is staffed by two consultant orthopaedic surgeons and two registrars. Indications for referral to the clinic for primary screening included a confirmed history of cerebral palsy, plus any of the following: 1) significant spasticity; 2) delayed walking or inability to walk; 3 ) reduced abduction;

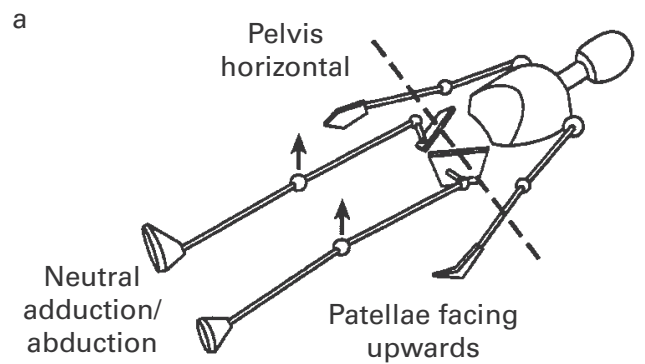

b

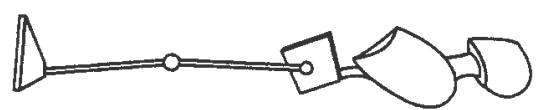

Incorrect - lordotic lumbar spine

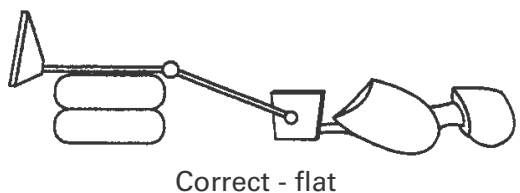

Fig. 1

\begin{abstract}
Diagram showing standardised positioning for AP pelvic radiographs for children with cerebral palsy. Figure 1a With the pelvis horizontal, the legs should be positioned almost parallel to each other (neutral abduction/adduction) with the patellae facing upwards. Figure $1 \mathrm{~b}-$ The pelvis should be flat and level. If there is a fixed flexion deformity giving a lordosis, the legs should be raised until the lumbar spine flattens.
\end{abstract}

4) concern of a physician or therapist, and 5) parental or carer concern.

Secondary screening included an anteroposterior (AP) radiograph of the hips. Standardised radiographs of the pelvis were obtained, with the patient supine, the pelvis as symmetrical as possible, the hips in neutral abduction/ adduction and the lumbar spine flat (Fig. 1). In the presence of fixed flexion deformity of the hip, both hips were flexed until the lumbar spine flattened in order to avoid excessive

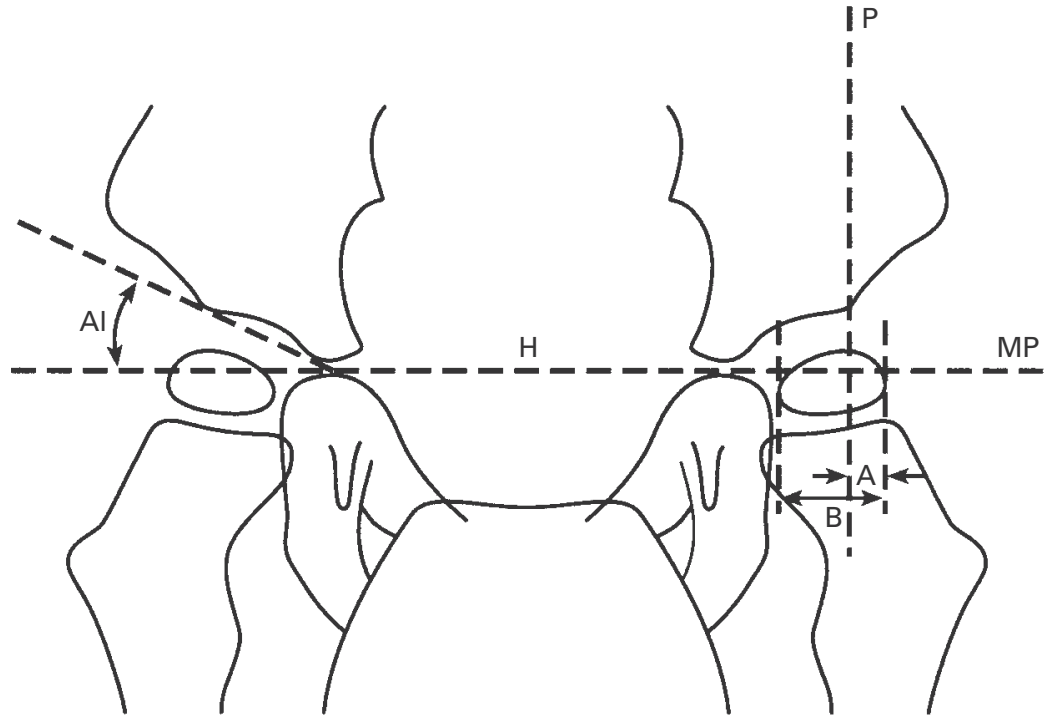

Fig. 2

Measurement of the migration percentage (MP) and acetabular index (AI). The MP represents that portion of ossified femoral head which has migrated laterally beyond Perkin's line. $\mathrm{MP}=\mathrm{A} / \mathrm{B} \times 100 \%$. The AI describes the slope of the acetabulum and is measured in degrees (H, Hilgenreiner's horizontal line between triradiate cartilages, P, Perkin's line drawn perpendicular to the $\mathrm{H}$-line at the lateral margin of the acetabulum). 
anterior tilt, which influences the accuracy of acetabular measurement. Prior education and demonstration regarding correct positioning were given to the Medical Imaging Department and all radiological request slips were stamped with positioning instructions. For measurement of migration percentage ${ }^{24}$ and acetabular index ${ }^{25,26}$ we used a carefully standardised technique, which has been shown to have good reproducibility ${ }^{27}$ (Fig. 2). Most hips have a clearly defined lateral acetabular margin and the measurement of the radiological indices is straightforward. Some, however, exhibit the 'gothic-arch' deformity of the lateral acetabular margin, because of eccentric pressure of the subluxated femoral head. In these hips, we recommend that the midpoint of the lateral margin be used. ${ }^{27}$ After these measurements had been recorded by the physiotherapist, the child was seen by the orthopaedic surgeon. The indications for preventive surgery were set as $>40 \%$ migration, an increase in migration of $>10 \%$ in one year, or an acetabular index $>27^{\circ}$. The indications for reconstructive surgery were progressive hip displacement, with migration of $>50 \%$ and increasing, despite adductor releases, appropriate bracing and modified seating. Most of the hips which were considered to be failures of soft-tissue surgery had reducible subluxations of the femoral head and were managed by bilateral femoral varus derotation osteotomies.

The effect of the HSC on surgical management was established by analysis of the surgical procedures carried out during the year before its commencement (1996) and each 12 months after its introduction, until August 2000. The surgical procedures were classified according to Miller et $\mathrm{al}^{2}$ as preventive, reconstructive or salvage (Table I).

In order to improve awareness of the need for hip surveillance a poster was designed and distributed to paediatricians and physiotherapy service providers. The child's community physiotherapist was invited to attend the clinic and correspondence outlining the child's clinical and radiological status was sent to the referral source and community physiotherapist after each visit.

\section{Results}

Patients. During the first three years of the clinic 133 children ( 75 boys, 58 girls) attended, and were followed up on a six- to 12 -monthly basis (412 visits). The mean age of referral to the clinic was 3.75 years (1 to 15$)$. This was significantly lower than the mean age of children attending the conventional surgical clinic. In the first year of the clinic, the mean age of referral was 4.58 years, compared with 3.05 years during its third year. Of these children, $65 \%$ had spastic quadriplegia, 30\% spastic diplegia and 5\% spastic hemiplegia. A few children had mixed movement disorders with elements of dystonic posturing or ataxia. All

Table I. Classification of surgical procedures of the management of spastic hip displacement in children with cerebral palsy by Miller et $\mathrm{al}^{2}$

\begin{tabular}{ll}
\hline Stage & Surgical procedures \\
\hline I. Preventive & Adductor longus release \\
(soft-tissue surgery) & Gracilis release \\
& Adductor brevis release \\
& Iliopsoas lengthening \\
& Obturator neurectomy - anterior branch only \\
& Femoral varus derotation osteotomy \\
II. Reconstructive & Pelvic osteotomy (Dega, San Diego, Pemberton) \\
(redirectional osteotomies) & Combined femoral and pelvic osteotomy \pm open reduction \\
& Excision of proximal femur \\
III. Salvage & Valgus osteotomy \\
& Interposition arthroplasty \\
& Replacement arthroplasty \\
& Arthrodesis \\
\hline
\end{tabular}

Table II. Total numbers of children managed by preventive reconstructive and salvage surgery before establishment of the Hip Surveillance Clinic (1996-1997) and after its establishment. All children in the first column, 1996 to 1997, came through the conventional surgical clinic. The children in each column, 1997 to 2000, came from both the Hip Surveillance Clinic and the conventional clinic. The number of hips in each category is twice the number of children, except for salvage surgery. Of the 24 children who had salvage surgery, in 16 children, it was bilateral and in the remaining eight, it was unilateral, for a total of 40 salvage operations.

\begin{tabular}{llllll}
\hline & Pre-HSC & HSC & & & \\
\cline { 3 - 6 } & $\mathbf{1 9 9 6}$ to & $\mathbf{1 9 9 7}$ to & $\mathbf{1 9 9 8}$ to & $\mathbf{1 9 9 9}$ to & Total 1997 to \\
Surgery & $\mathbf{1 9 9 7}$ & $\mathbf{1 9 9 8}$ & $\mathbf{1 9 9 9}$ & $\mathbf{2 0 0 0}$ & $\mathbf{2 0 0 0}$ \\
\hline Preventive & 36 & 41 & 53 & 61 & 155 \\
Reconstructive & 26 & 49 & 35 & 25 & 109 \\
Salvage & 8 & 10 & 6 & 0 & 16 \\
Total & 70 & 100 & 94 & 86 & 280 \\
\hline
\end{tabular}


were considered to have significant spasticity. Children were referred to the clinic by paediatricians (45\%), community/private paediatric physiotherapists (20\%) and orthopaedic surgeons $(35 \%)$.

Progression to surgery. The number of children requiring surgery and the type of surgery are summarised in Table II. These figures are the combined figures from the HSC and the conventional surgical clinic. Of those referred to the HSC, 61 children (46\%) have been managed by surgery, the others remain under surveillance. A total of 52 children from the HSC was successfully managed by preventive surgery. Adductor releases and femoral osteotomies were required in the remaining nine children, who presented with migration $>50 \%$. Both the migration percentage at presentation and the incidence of established dislocation were much lower in children who presented to the HSC than the conventional clinic.

Almost one-third of preventive operations which were undertaken during the study period was for children who presented to the HSC and who presumably would have had a significant delay in presentation, if we had relied on the conventional clinic. Surgery to prevent dislocation of the hip has increased substantially, because of early identification of 'silent' hip subluxation. The number of children requiring reconstructive surgery has decreased and the need for salvage surgery has been eliminated, at least temporarily. The mean time for children from the HSC to progress to preventive surgery was 12 weeks ( 1 to 28 ) compared with 19 ( 1 to 44 ) for children in 1996 , managed by the conventional waiting list. The hospital management accepted the urgency of preventive surgery and provided additional operating lists. The mean age of HSC children at which preventive surgery was undertaken was 4.2 years (1.5 to 7.6), compared with 8.3 (1.4 to 19) for children in 1996, managed by the conventional clinic.

The 109 children managed by reconstructive surgery between 1997 and 2000 had one-stage bilateral hip reconstructions, including adductor lengthening, femoral varus derotation osteotomies, and in selected hips, pelvic osteotomy. The short-term results of reconstructive surgery have been good with no hips redislocating, remaining painful or requiring salvage surgery, which was carried out for endstage spastic hip disease in 16 children between 1997 and 2000 , using excision of the femoral head or valgus femoral osteotomy, with variable results. ${ }^{2,19,22}$

\section{Discussion}

A clinic such as our HSC, co-ordinated and run by physiotherapists and orthopaedic surgeons, allows for systematic monitoring, follow-up and intervention for children with spastic hip disease. The criteria of the World Health Organisation for a good screening programme as outlined in Wilson and Jungner ${ }^{28}$ are given in Table III.

We believe that screening for spastic hip disease in the 'at-risk' population fulfils all these criteria. The high pre-
Table III. World Health Organisation criteria for screening programme

\begin{tabular}{cl}
\hline 1. & Important health problem \\
2. & Acceptable treatment \\
3. & Diagnosis and treatment available \\
4. & Recognisable - latent or early symptomatic stage \\
5. & Suitable test or examination exists \\
6. & Test acceptable to population \\
7. & Natural history adequately understood \\
8. & Agreed policy on whom to treat \\
9. & Cost benefit \\
10. & Continuous process
\end{tabular}

valence of spastic hip disease in the 'at-risk' population and the availability of a good diagnostic test are the principal reasons for the success of hip surveillance in cerebral palsy. Of the children presenting to the HSC $46 \%$ required surgery within four years of presentation.

Reimers $^{24}$ established the validity of the migration percentage as a measure of hip displacement, in spastic hip disease. We have shown excellent reproducibility of the migration percentage in a recent study, confirming the use of this simple and widely available measure. ${ }^{27}$

Although the principle of screening for spastic hip disease is not new, there are no generally agreed guidelines. The recommendations of Scrutton and Baird ${ }^{11}$ for a hip surveillance programme for children with cerebral palsy were that all children with bilateral cerebral palsy require a hip radiograph by the age of 30 months or earlier if there are abnormal clinical signs. In addition, radiographs need to be taken in a standardised position in order to obtain valid, serial measurements of displacement of the hip. Radiographs should be repeated at six-monthly intervals because displacement can occur rapidly in some children (Fig. 3). Other authors have noted that hips may begin to displace as early as 18 months of age. $9,24,29$ We advocate that all children with bilateral cerebral palsy should have a pelvic radiograph before this age.

Delayed detection of hip displacement can be disastrous in children with cerebral palsy and it is imperative that health professionals understand the high incidence and serious consequences of neglected hip displacement. ${ }^{2}$ At first sight, hip surveillance seems deceptively simple. It is tempting to think that it can be carried out by conventional hospital and community-based agencies. Unfortunately, there is no evidence that traditional clinical practice and selective referral to a specialist surgical clinic are adequate. In our centre, before 1996, many children were frequently not seen until their hips were dislocated and some were then too late for reconstructive surgery at first referral. Some children had never had their hips studied radiographically; in others this had been done but early hip displacement was not recognised or was ignored. Early referral for hip surveillance should be standard practice for every child with bilateral cerebral palsy. Some paediatricians and physiotherapists are reluctant to refer younger children with cerebral palsy to orthopaedic surgeons and 


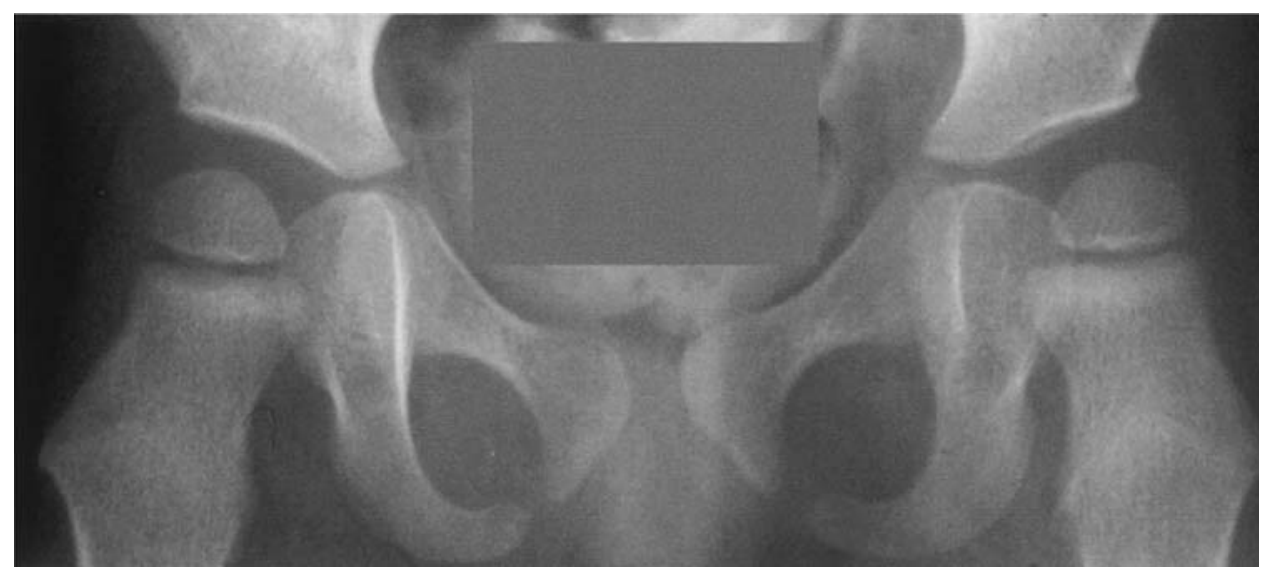

Fig. 3a

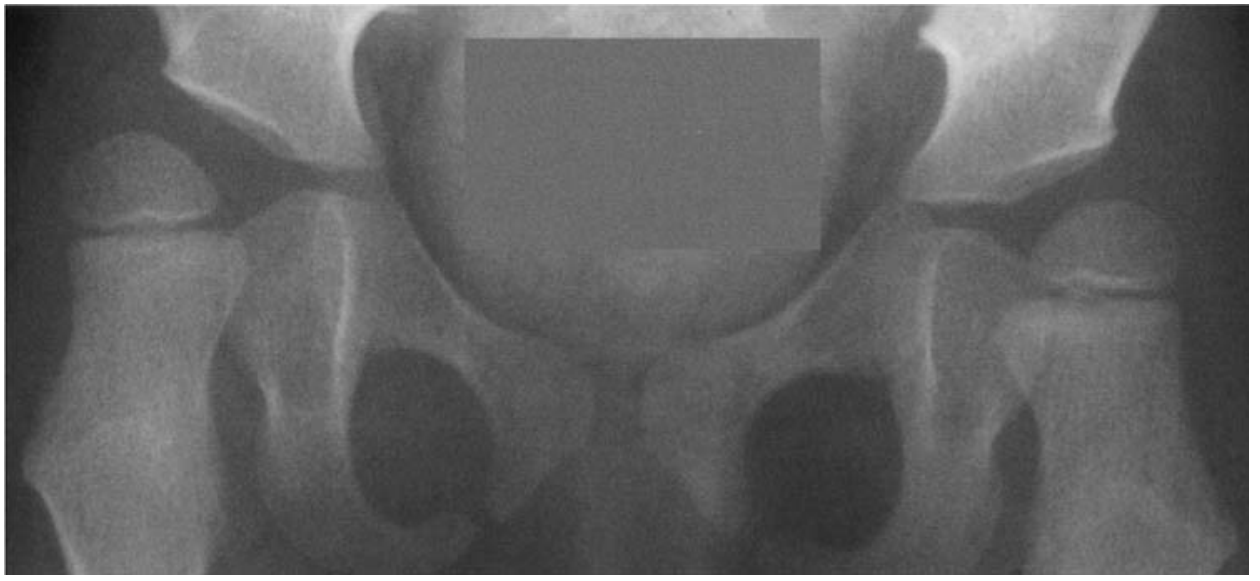

Fig. 3b

AP radiographs of a child with spastic quadriplegia. Figure $3 \mathrm{a}-$ At presentation at 21 months the right migration percentage is 23 and the left 32 . Figure $3 b-$ At follow-up at age 29 months, the right migration percentage is 61 and the left 45 .

this may delay the detection of hip problems. Unless the results of hip surveillance and surgical intervention are of a high standard, the programme may not be supported by those who have first contact with the child, generally, community-based paediatricians and physiotherapists. The co-operation of the parents and carers in a regular screening programme is very important. We believe that the userfriendly, non-intimidating atmosphere of the HSC was very important in ensuring complete follow-up and in reducing the age at first referral.

Although there is a consensus in the literature as to the need for preventive surgery in children who have cerebral palsy and progressive migration of the hip, there is less agreement on the threshold for intervention. Published thresholds for the migration percentage range from $50 \%{ }^{30}$ to $<30 \% .^{31}$ Miller et al ${ }^{16}$ recommended soft-tissue surgery when the migration percentage is between $25 \%$ and $50 \%$, depending on the range of hip abduction. Cornell et $\mathrm{al}^{32}$ found that a preoperative migration percentage of $<40 \%$ was the most significant predictor of a satisfactory outcome after soft-tissue surgery. Although the acetabular index was not a significant predictor, children with a value of less than $27^{\circ}$ did better after soft-tissue surgery alone. In addition, surgery was only effective in hips with a migration percentage of between $40 \%$ and $60 \%$, if early and adequate postoperative bracing was attainable. ${ }^{32}$ The decision to consider surgery in the management of hips which are at risk is usually based on two or more repeated radiographs over time. We chose $40 \%$ as our threshold for advising surgical intervention and tailored the adductor release surgery according to the clinical and radiological picture. ${ }^{2,33}$

Late intervention is primarily related to late detection and referral. The surgical literature on the management of spastic hip disease during the past decade has been dominated by reports of reconstructive or salvage surgery. ${ }^{18,34-40}$ There have been comparatively few reports on preventive 


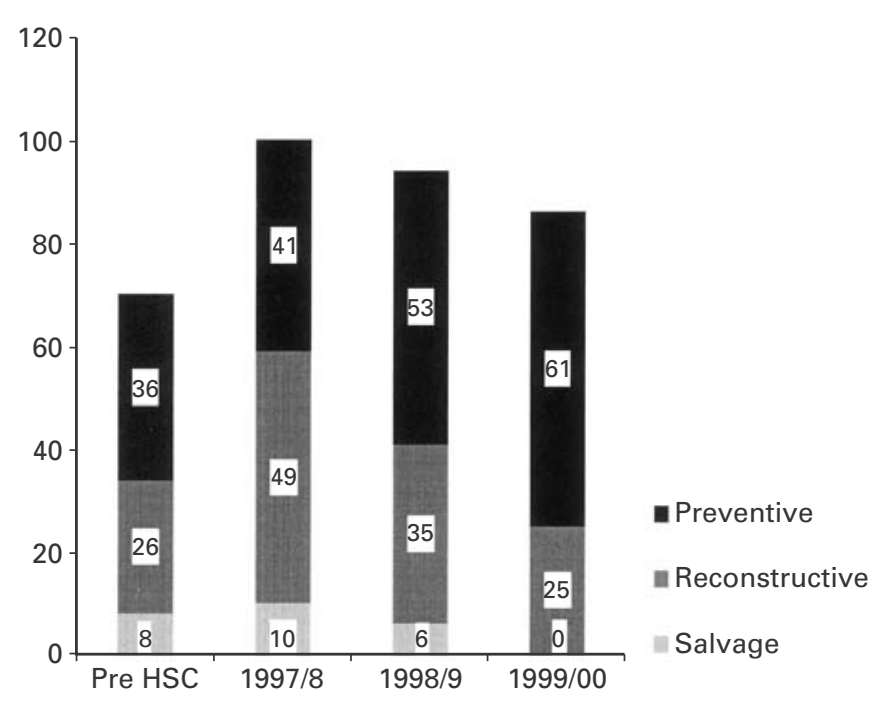

Fig. 4

Graph showing the total number of preventive, reconstructive and salvage surgical procedures undertaken in the year before the HSC began and at 12-monthly intervals afterwards.

surgery or approaches to change surgical practice. ${ }^{16,32}$ Reconstructive surgery is dominated by reports of onestage open reduction, femoral and pelvic osteotomy, with few authors addressing the issue as to why these major interventions are required. ${ }^{34,36,37}$

Our aim in establishing the HSC was to try to improve the outcome of spastic hip disease by early detection and intervention. As a result, 52 children were identified at an early stage in the evolution of spastic hip disease and were managed by preventive surgery at a mean of 12 weeks after diagnosis. Reconstructive surgery may be required for some children, but we hope to have abolished end-stage, spastic hip disease and the need for salvage surgery. The number of reconstructive procedures is falling which we believe is due to the preventive surgery which we are undertaking at an earlier stage in the process of the disease. The need for salvage surgery has been eliminated, at least temporarily (Fig. 4).

Soft-tissue surgery does not always prevent the need for reconstructive surgery. ${ }^{2,4,9,16}$ Nine children who presented to the HSC required reconstructive surgery for advanced subluxation, at first presentation. Of the 155 children whose hips were managed by preventive surgery in our study, 12 have required reconstructive surgery at a mean follow-up of only 32 months. This figure will probably increase with further follow-up. The failure rate for preventive surgery is probably about $25 \%$. ${ }^{2,16,22,30,31}$ Reconstructive surgery has a low failure rate and very rarely progresses to salvage surgery ${ }^{2,18,34,37}$ which is primarily required because of late presentation, not failure of surgery. ${ }^{2,4,9,19,23,35}$ Some hips managed by reconstructive surgery may be painful for up to a year after surgery. Some may require additional procedures, but very few will need salvage surgery., ${ }^{2,18,22,34,38}$
The 109 children managed by reconstructive surgery in our study have a mean follow-up of only 28 months. There have been no additional hip operations, apart from removal of implants. No hips have required salvage surgery and on current clinical and radiological grounds, none is likely to. We emphasise that our results are preliminary and that follow-up of this series of patients until skeletal maturity is required.

From the findings of this study, we would make the following recommendations.

1) All children with bilateral cerebral palsy need a pelvic radiograph by the age of 18 months.

2) Children with spastic quadriplegia or diplegia should be monitored, clinically and radiologically, every six to 12 months.

3) Standardised protocols for positioning the child and measuring the migration percentage and acetabular index on radiographs should be used.

4) These recommendations may be most successful in the context of a screening programme, combined with a hospital and community education programme.

5) Early detection of spastic hip displacement combined with early surgical intervention can prevent dislocation of the hip and avoid the need for more invasive surgery.

This study is supported by the National Health and Medical Research Council of Australia through grant number 980753 and the Murdoch Childrens Research Institute. We would like to acknowledge the assistance and support of the following groups: our colleagues in the Medical Imaging department, the departments of Child Development and Rehabilitation, Paediatric Medicine, Paediatric Neurology and Physiotherapy at the Royal Children's Hospital and the Physiotherapists, Paediatricians and General Practitioners in the community.

No benefits in any form have been received or will be received from a commercial party related directly or indirectly to the subject of this article.

\section{References}

1. Cornell MS. The hip in cerebral palsy. Dev Med Child Neurol 1995;37:3-18.

2. Miller F, Dabney KW, Rang M. Complications in cerebral palsy treatment. In: Epps $\mathrm{CH}$ Jr, Bowen JR, eds. Complications in pediatric orthopaedic surgery. Philadelphia: Lippincott Company, 1995:477-544.

3. Lonstein JE, Beck K. Hip dislocation and subluxation in cerebral palsy. J Pediatr Orthop 1986;6:521-6.

4. Rang M. Cerebral palsy. In: Morrissy RT, ed. Lovell and Winter's pediatric orthopaedics. 3rd ed. Philadelphia: Lippincott Company, 1990:465-506.

5. Bagg MR, Farber J, Miller F. Long-term follow-up of hip subluxation in cerebral palsy patients. J Pediatr Orthop 1993;13:32-6.

6. Cooperman DR, Bartucci E, Dietrick E, Millar EA. Hip dislocation in spastic cerebral palsy: long term consequences. J Pediatr Orthop 1987;7:268-76

7. Moreau M, Drummond DS, Rogala E, Ashworth A, Porter T. Natural history of the dislocated hip in spastic cerebral palsy. Dev Med Child Neurol 1979;21:749-53.

8. Pritchet J. The untreated unstable hip in severe cerebral palsy. Clin Orthop 1983;173:169-72.

9. Samilson RL, Tsou P, Aamoth G, Green WM. Dislocation and subluxation of the hip in cerebral palsy: pathogenesis, natural history and management. J Bone Joint Surg [Am] 1972;54-A:863-73.

10. Letts M, Shapiro L, Mulder K, Klassen O. The windblown hip syndrome in total body cerebral palsy. J Pediatr Orthop 1984;4:55-62. 
11. Scrutton D, Baird G. Surveillance measures of the hips of children with bilateral cerebral palsy. Arch Child 1997;76:381-4.

12. Beals RK. Developmental changes in the femur and acetabulum in spastic paraplegia and diplegia. Dev Med Child Neurol 1969;11:303-13.

13. Kalen V, Bleck EE. Prevention of spastic paralytic dislocation of the hip. Dev Med Child Neurol 1985;27:17-24.

14. Harris NH, Lloyd-Roberts GC, Gallien R. Acetabular development in congenital dislocation of the hip: with special reference to the indications for acetabuloplasty and pelvic or femoral realignment osteotomy. J Bone Joint Surg [Br] 1975;57-B:46-52.

15. Scrutton D. The early management of hips in cerebral palsy. Dev Med Child Neurol 1989;31:108-16.

16. Miller F, Dias RC, Dabney KW, Lipton GE, Triana M. Soft-tissue release for spastic hip subluxation in cerebral palsy. J Pediatr Orthop 1997; 17:571-84.

17. Eilert R, MacEwan G. Varus derotational osteotomy of the femur in cerebral palsy. Clin Orthop 1977;125:168-72.

18. Miller F, Girardi H, Lipton GE, et al. Reconstruction of the dysplastic hip with peri-ilial pelvic and femoral osteotomy followed by immediate mobilization. J Pediatr Orthop 1997;17:592-602.

19. Castle M, Schneider C. Proximal femoral resection-interposition arthroplasty. J Bone Joint Surg [Am] 1978;68-A:1051-4.

20. Root L, Siegal T. Osteotomy of the hip in children: posterior approach. J Bone Joint Surg [Am] 1980;62-A:571-5.

21. Tylkowski C, Rosenthal R, Simon S. Proximal femoral osteotomy in cerebral palsy. Clin Orthop 1980;151:183-92.

22. Bleck EE. Orthopaedic management in cerebral palsy. London, MacKeith Press 1987;99-371, 440-70.

23. Koffman M. Proximal femoral resection or total hip replacement in severely disabled cerebral-spastic patients. Orthop Clin North Am 1981;12:91-100.

24. Reimers J. The stability of the hip in children: a radiological study of the results of muscle surgery in cerebral palsy. Acta Orthop Scand 1980:Suppl 184.

25. Hilgenreiner H. Zur fruhdiagnose und fruhbehandlung der angeboronen huftgelenkeverrenkung. Med Klin 1925;21:1385-425.

26. Kleinberg S, Lieberman HS. Acetabular index in infants in relation to congenital dislocation of the hip. Arch Surg 1936;32:1049-54.
27. Parrott JK, Boyd RN, Smithson FL, et al. Reliability of radiological measures of hip displacement in children with spastic cerebral palsy. Dev Med Child Neurol 2000;S83,42:5-6.

28. Wilson JMG, Jungner G. Publ Hlth Pap W. H. O. No 34. 1968.

29. Tachdjian MO, Minear WL. Hip dislocation in cerebral palsy. J Bone Joint Surg [Am] 1956;38-A:1358-64.

30. Silver RL, Rang M, Chan J, de la Garza RJ. Adductor release in nonambulant children with cerebral palsy. J Paediatr Orthop 1985;5:672-7.

31. Onimus M, Allamel G, Manzone P, Laurain JM. Prevention of hip dislocation in cerebral palsy by early psoas and adductors tenotomies. J Pediatr Orthop 1991;11:432-35.

32. Cornell MS, Hatrick NC, Boyd RN, Baird G, Spencer JD. The hip in children with cerebral palsy: predicting the outcome of soft tissue surgery. Clin Orthop 1997;340:165-71.

33. Barwood S, Baillieu C, Boyd R, et al. Analgesic effects of botulinum toxin A: a randomized placebo-controlled clinical trial. Dev Med Child Neurol 2000;42:116-21.

34. McNerney NP, Mubarak SJ, Wenger DR. One-stage correction of the dysplastic hip in cerebral palsy with the San Diego acetabuloplasty: results and complications in 104 hips. J Pediatr Orthop 2000;20:93-103.

35. Gamble JG, Rinsky LA, Bleck EE. Established hip dislocations in children with cerebral palsy. Clin Orthop 1990;253:90-9.

36. Gordon JE, Capelli AM, Strecker WB, Delgado ED, Shoenecker PL. Pemberton pelvic osteotomy and varus rotational osteotomy in the treatment of acetabular dysplasia in patients with static encephalopathy. J Bone Joint Surg [Am] 1996;78-A:1863-71.

37. Mubarak SJ, Valencia FG, Wenger DR. One-stage correction of the spastic dislocated hip: use of pericapsular acetabuloplasty to improve coverage. J Bone Joint Surg [Am] 1992;74-A:1347-57.

38. Root L, Laplaza FJ, Brourman S, Angel DH. The severely unstable hip in cerebral palsy: treatment with open reduction, pelvic osteotomy, and femoral osteotomy with shortening. J Bone Joint Surg [Am] 1995;77-A:703-12.

39. Shea KG, Coleman SS, Carroll K, Stevens P, Van Boerum DH. Pemberton percapsular osteotomy to treat a dysplastic hip in cerebral palsy. J Bone Joint Surg [Am] 1997;79-A:1342-51.

40. Zuckerman JD, Steheli LT, McLaughlin JF. Acetabular augmentation for progressive hip subluxation in cerebral palsy. $J$ Pediatr Orthop 1984;4:436-42. 